\title{
The importance of postoperative control: adrenal insufficiency after unilateral adrenalectomy for Conn's syndrome. A case study
}

\author{
Marta Sołtysiak, Paweł Sołtysiak, Anna Brzeska, Krystyna Widecka
}

Department of Hypertensiology and Internal Diseases Pomeranian Medical University

\begin{abstract}
According to the current guidelines of the Polish Society of Hypertension on the management of primary aldosteronism (PA) associated with aldosterone-producing adenoma, the treatment of choice is unilateral laparoscopic adrenalectomy. Isolated deficiency of aldosterone after adrenalectomy for Conn's syndrome is rare. The literature finds few reports on postoperative hypoaldosteronism requiring mineralocorticoid replacement. In this case study we present a patient who developed postoperative hypoaldosteronism.

key words: Conn's syndrome, adrenalectomy, hypoaldosteronism, hyperkalaemia

Arterial Hypertens. 2016, vol. 20, no. 2, pages: 73-74

DOI: $10.5603 / A H .2016 .0012$
\end{abstract}

\section{Case study}

A 56-year-old patient with long-standing history of hypertension, hypokalaemia, and left adrenal gland tumour was admitted to the Department of Hypertension for the hormonal diagnosis. On physical examination, there were no significant deviations. Performed laboratory tests revealed hypokalaemia of $2.07 \mathrm{mmol} / \mathrm{l}$ (normal range $3.5-5.5 \mathrm{mmol} / \mathrm{l}$ ) and hypercholesterolaemia of $285 \mathrm{mg} / \mathrm{dl}$ (normal range up to $200 \mathrm{mg} / \mathrm{dl})$. Her baseline aldosterone level was $341 \mathrm{pg} / \mathrm{ml}$ (normal range $10-160 \mathrm{pg} / \mathrm{ml}$ ), plasma renin activity (PRA) was $0.97 \mathrm{ng} / \mathrm{ml} / \mathrm{h}$ (normal range 0.51-2.64), aldosterone/rennin ratio (ARR) was 35.2 with a positive saline suppression test (post saline aldosterone $190 \mathrm{pg} / \mathrm{ml}$, plasma renin activity of $0.53 \mathrm{ng} / \mathrm{ml} / \mathrm{h}$, ARR 35.8). Mean arterial pressure in 24-hour ambulatory blood pressure monitoring was 156/94 mm Hg. CT scan confirmed the left adrenal tumour size $1.6 \times 1.4 \times 1.7 \mathrm{~cm}$, classified as adenoma (Figure 1). Perindopril and spironolactone was implemented to the antihypertensive treatment. Having regard to the entire clinical picture, the patient was diagnosed with Conn's syndrome. She was referred for surgical management and discharged home on the third postoperative day with the recommendation of the continuation of current antihypertensive therapy except for spironolactone. After two months the patient came to the emergency room with complaints of weakness, headaches, and low blood pressure (BP) measurements at home, oscillating around 90/ $160 \mathrm{~mm} \mathrm{Hg}$. Laboratory tests revealed hyperkalaemia of $5.67 \mathrm{mmol} / \mathrm{l}$ and decreased level of sodium of 132 $\mathrm{mmol} / \mathrm{l}$ (normal range 135-145 mmol/l). During hospitalization, she was diagnosed with aldosterone deficiency and started on aldosterone replacement therapy with fludrocortisone. Normalization of ion levels and BP was observed as a result of treatment. 


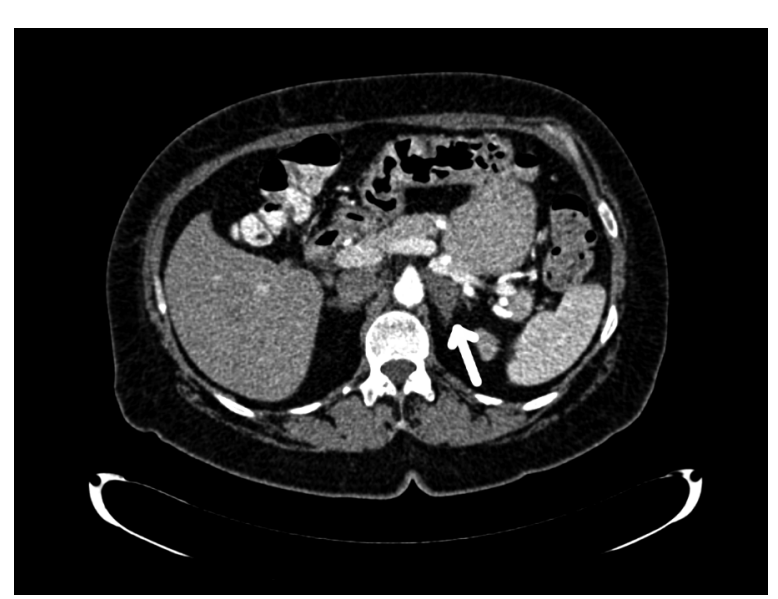

Figure 1. The patient's CT scan

\section{Discussion}

According to the current guidelines of the Polish Society of Hypertension on the management of primary aldosteronism (PA) associated with aldosterone-producing adenoma, the treatment of choice is unilateral laparoscopic adrenalectomy [1]. The literature finds few reports on postoperative hypoaldosteronism requiring mineralocorticoid replacement [2-6]. Literature data indicate that some patients who undergo adrenalectomy for PA present postoperative hyperkalaemia associated with the inability of the remaining adrenal gland to compensatory aldosterone production $[2,7,8]$.

In 2010, Huang et al. reported a case of 62-yearold man with severe hyperkalaemia after adrenalectomy - laboratory tests showed a high level of PRA and low level of aldosterone, normal levels of cortisol and ACTH suggesting hypoaldosteronism as the cause of hypokalaemia [3]. Similarly, in 2015, Yorke et al. described a case of 66-year-old female operated for Conn's syndrome, with subsequent postoperative hyperkalaemia and hypotension, successfully treated with fludrocortisone [2].

As reported by Gadallah et al., the gradual normalization of hyperkalaemia and the aldosterone level meant this suppression is reversible [5]. In fact, some studies suggest that postoperative deficiency of aldosterone is temporary and aldosterone level is normalized within approximately six months [6,9-11]. In opposition, Gordon et al. suggest that untreated hypoaldosteronism may not subside spontaneously and their opinion is based on a prospective study of a group of 26 patients after adrenalectomy for Conn's syndrome, among whom, in the two-year follow-up period, $27 \%$ had a systolic blood pressure below the fifth percentile, which was associated with aldosterone deficiency [4].

The literature describes the heterogeneous data on the relationship between preoperative spironolactone therapy and postoperative aldosterone deficiency. Morimoto et al. suggest that the pretreatment with spironolactone promotes the normalization of the juxtaglomerular apparatus function postoperatively [12]. In contrast, Fisher $e t$ al. indicate that preoperational spironolactone therapy has no impact on the incidence of subsequent hypoaldosteronism. Based on their own study, they described age and impaired renal function as the risk factors [13].

In summary, the reports of aldosterone deficiency after adrenalectomy for Conn's syndrome emphasize the role of the recovery control in these patients, in particular the elderly and those with impaired renal function.

\section{References}

1. Tykarski A., Narkiewicz K., Gaciong Z. et al. 2015 Guidelines for the Management of Hypertension. Arterial Hypertens. 2015; 4: 153-173.

2. Yorke E., Stafford S., Holmes D., Sheth S., Melcka A. Aldosterone deficiency after unilateral adrenalectomy for Conn's syndrome: a case report and literature review. Int. J. Surg. Case Rep. 2015; 7: 141-144.

3. Huang W., Chau T., Wu S. et al. Prolonged hyperkalemia following unilateral adrenalectomy for primary hyperaldosteronism. Clin. Nephrol. 2010; 5: 392-397.

4. Gordon R., Hawkins P., Hamlet S. et al. Unexpected incidence of low blood pressure 2 years after unilateral adrenalectomy for primary aldosteronism. Clin. Exp. Pharmacol. Physiol. 1989; 16: 281-286.

5. Gadallah M., Kayyas Y., Boules F. Reversible suppression of the renin-aldosterone axis after unilateral adrenalectomy for adrenal adenoma. Am. J. Kidney Dis. 1998; 32: 160-163.

6. Biglieri E., Slaton Jr P., Silen W. et al. Post-operative studies of adrenal function in primary aldosteronism. J. Clin. Endocrinol. Metab. 1966; 5: 553-558.

7. Gill Jr J. Hyperaldosteronism. In: Becker K., Bilezikian J. Bremner W. Principles and Practice of Endocrinology and Metabolism. 2nd ed. Lippincott Co., Philadelphia 1995: 716-734.

8. Kaplan M., Victor R. Primary aldosteronism. In: Clinical Hypertension. 7th ed. Lippincott Williams \& Wilkins, Baltimore 1998: 365-382.

9. Bravo E., Dustan H., Tarazi R. Selective hypoaldosteronism despite prolonged pre- and post- operative hypereninemia in primary aldosteronism. J. Clin. Endocrinol. Metab. 1975: 41; 611-617.

10. Groth H., Vetter W., Stimpel M. et al. Adrenalectomy in primary aldosteronism: a long term follow up study. Cardiology 1985: 72; 107-116.

11. Kawasaki T., Uezono K., Ueno M. et al. Influence on unilateral adrenalectomy on renin-angiotensin-aldosterone system in primary aldosteronism. Jpn. Heart J. 1980: 5; 681-692.

12. Morimoto S., Takeda R., Murakami M. et al. Does prolonged pretreatment with large doses of spironolactone hasten recovery from juxtaglomerular-adrenal suppression in primary aldosteronism. J. Clin. Endocrinol. 1970: 31; 659-664.

13. Fisher E., Hanslik G., Pallauf A. et al. Prolonged zona glomerulosa insufficiency causing hyperkalemia in primary aldosteronism after adrenalectomy. J. Clin. Endrocinol. Metab. 2012: 97; 3965-3973. 